\title{
Effects of Dexamethasone on Tissue Injury and Reconstruction in Ethanol/Steroid Injection Therapy for Allergic Rhinitis
}

Masaru Kimura ${ }^{1 \#}$, Noriko Sugaya ${ }^{1 \#}$, Koji Kimata ${ }^{1 *}$, Masanao Kawachi ${ }^{2}$, Miwa Sawada ${ }^{3}$, Hiroyuki Kuroda ${ }^{2}$, Mineo Takei ${ }^{2}$, Shigeru Inafuku and Men-Dar $\mathbf{W u}^{1}$

${ }^{1}$ Research Complex for the Medicine Frontiers, Aichi Medical University, Japan

${ }^{2}$ Pharmacological Research, Central Research Laboratories, Zeria Pharmaceutical Co., Ltd., Japan

${ }^{3}$ Toxicology \& Pharmacokinetics Research, Central Research Laboratories, Zeria Pharmaceutical Co., Ltd., Japan

\#Contributed equally to this work

\begin{abstract}
Background: Conventional therapies involving radiofrequency tissue ablation or laser cauterization for allergic rhinitis are accompanied by lesioning and restoration of the mucosa, which are important healing processes for this therapy but difficult to control in their extent. To overcome this problem, we developed a therapeutic method based on the injection of ethanol $(E)$ containing a glucocorticoid into the nasal mucosa; however, the mechanistic aspects of this method remain to be investigated.
\end{abstract}

Objective: We first developed a mouse model of the tissue injury for therapeutic processes of allergic rhinitis by using skin tissues and then clarified the effectiveness of the glucocorticoid in the healing process of the tissue lesion caused by ethanol using the model.

Methods: We injected $70 \%(\mathrm{v} / \mathrm{v}) \mathrm{E}$ containing $0.1 \%$ dexamethasone (E/Dex), $70 \%(\mathrm{v} / \mathrm{v}) \mathrm{E}$, or saline (Sa) into the dermis of mouse skin. Histological analysis of tissue damage, quantitative analyses of inflammatory cytokine and chemokine expressions, and histological and quantitative analyses of some extracellular matrix molecules were performed.

Results: Histological comparisons of damaged tissues performed using the skin model qualified it as an effective mimic of the nasal mucosa. In the model, the inclusion of Dex in the injection of E/Dex dramatically ameliorated tissue damage by significantly attenuating expressions of neutrophil chemotactic chemokines, such as keratinocyte chemokine and macrophage inflammatory protein-2, and pro-inflammatory cytokines, such as interleukin-1 $\beta$, interleukin-6, and osteopontin, compared to the injection of $E$ alone. Inflammatory cell recruitment was also suppressed after the injection of E/Dex. Hyaluronan and versican expression increased after $\mathrm{E}$ injection, but hyaluronan expression was markedly suppressed after E/Dex injection.

Conclusion: We confirmed that Dex alleviates the tissue damage caused by ethanol-induced activated neutrophils via suppression of neutrophil chemotactic chemokines and pro-inflammatory cytokines and reduction of the inflammatory extracellular matrix, which reveals the effectiveness of glucocorticoids in our developing injection therapy.

Keywords: Allergic rhinitis; Skin model; Glucocorticoid; Dexamethasone; Cytokines; Chemokine; Extracellular matrix

Abbreviations: E: Ethanol; E/Dex: 70\% (v/v) Ethanol containing 0.1\% Dexamethasone; Dex: Dexamethasone; HA: Hyaluronan; HAS: Hyaluronan Synthase; HE: Hematoxylin and Eosin; IL: Interleukin; KC: Keratinocyte Chemokine; MIF: Migration Inhibitory Factor; MIP2: Macrophage Inflammatory Protein-2; mRNA: Messenger RNA; OPN: Osteopontin; Sa: Saline; GAPDH: Glyceraldehyde 3-Phosphate Dehydrogenase

\section{Introduction}

Conventional therapies involving radiofrequency tissue ablation or laser cauterization for allergic rhinitis are accompanied by lesioning and restoration of the mucosa, which are important healing processes. The extent of these processes is difficult to control in these therapies, however, and often leads to mucosal erosion and severe pain for patients. To address this problem, we attempted to develop a new clinical treatment for allergic rhinitis that mitigates requisite mucosal damage through the injection of ethanol (E) containing a glucocorticoid into the inferior turbinate mucosa in taking advantage of the superior degeneration and coagulation capabilities of $\mathrm{E}$ in tissues [1,2]. We predicted that considerable technical skill would be required to inject ethanol into the nasal mucosa without spreading tissue damage to the mucosal surface. We overcame this technical problem by alleviating tissue damage as much as possible in the early treatment phase after the injection because injury is augmented by an inflammatory response characterized by neutrophil infiltration that accompanies tissue damage upon ethanol administration [3]. In doing so, we found that adding a glucocorticoid with potent anti-inflammatory activity alleviated tissue damage and by preserving the contractile effects of tissue itself, reduced the infiltration of inflammatory cells, especially neutrophils, into inflamed sites in a dose-dependent manner [3]. The clinical application of this E/steroid mixture as so-called submucosal E/steroid injection

*Corresponding author: Dr. Koji Kimata, Research Complex for the Medicine Frontiers, Aichi Medical University, 21 Karimata, Yazako, Nagakute, Aichi 480-1195, Japan Tel: +81-561-61-1898; Fax: +81-561-61-1896l; E-mail: kimata@aichi-med-u.ac.jp

Received February 05, 2012; Accepted March 22, 2012; Published March 27, 2012

Citation: Kimura M, Sugaya N, Kimata K, Kawachi M, Sawada M, et al. (2012) Effects of Dexamethasone on Tissue Injury and Reconstruction in Ethanol/Steroid Injection Therapy for Allergic Rhinitis. J Aller Ther S5:005. doi:10.4172/2155-6121. S5-005

Copyright: ( $) 2012$ Kimura M, et al. This is an open-access article distributed unde the terms of the Creative Commons Attribution License, which permits unrestricted use, distribution, and reproduction in any medium, provided the original author and source are credited. 
Citation: Kimura M, Sugaya N, Kimata K, Kawachi M, Sawada M, et al. (2012) Effects of Dexamethasone on Tissue Injury and Reconstruction in Ethanol/Steroid Injection Therapy for Allergic Rhinitis. J Aller Ther S5:005. doi:10.4172/2155-6121.S5-005

Page 2 of 9

therapy has already been attempted, and preliminary results of the treatment have been reported as a pilot study [4].

During inflammatory processes, several lineages of inflammatory cells are recruited to sites of tissue damage with overlapping time courses. Both neutrophils and macrophages are known to influence various aspects of inflammation and tissue repair. Neutrophils are major cell types that play a role in host defense mechanisms. They rapidly respond to tissue damage or infections by exuding and migrating to sites of infection and damage [5]. In other words, neutrophils normally work to protect living organisms from bacterial infections and other tissue injuries. Tissue damage is also known to be exacerbated by degradative enzymes and reactive oxygen species, which are produced in activated neutrophils by recruitment to the injured sites [6-8]. In addition, many chemotactic factors have been shown to facilitate the migration of neutrophils and macrophages to infection and damage sites, among which CXC chemokines can affect neutrophils, whereas CC chemokines have the capability to affect macrophages [9]. Glucocorticoids such as dexamethasone (Dex) are potent anti-inflammatory agents that also suppress chemokine production [10].

Although the physiological and pathological actions of $\mathrm{E}$ and glucocorticoids have been studied substantially, as described above, further investigation is required to determine the mechanism through which Dex is effective and whether it is appropriate as an anti-inflammatory agent in tissue injury and reconstruction during submucosal E/steroid injection therapy. Therefore, in vivo experimental models for this therapy were contrived. Although mice or rats are ideal model animals in terms of handling and maintenance, their target tissues (nasal mucosa) are too small to be subjected to such treatment and subsequent analyses. The objectives of this study were first to establish E tissue damage models by using mouse skin-which appears to have greater availability and applicability as research material-as an in vivo experimental model for inferior turbinate submucosal $\mathrm{E} /$ steroid injection therapy and then to use the model to clarify the mechanism by which glucocorticoids suppress initial inflammatory reactions in healing processes in terms of inflammatory cytokine and chemokine expression and inflammatory cell infiltration and recruitment.

\section{Materials and Methods}

\section{Materials}

Biotinylated rat anti-mouse Ly-6G monoclonal antibody (clone NIMP-R14) was purchased from Hycult Biotech (Uden, The Netherlands). Rat anti-mouse F4/80 monoclonal antibody (clone BM8) was from BMA Biomedicals (Augst, Switzerland). Rabbit anti-mouse versican (GAG beta domain) antibody was from Millipore (Billerica, MA, USA). Alexa Fluor 546 goat anti-rabbit IgG and Alexa Fluor 488 conjugated streptavidin were purchased from Life Technologies (Carlsbad, CA, USA). DyLight 549 goat anti-rat IgG [H\&L] was from Rockland Immunochemicals Inc. (Gilbertsville, PA, USA). Chondroitinase $\mathrm{ABC}$ and biotinylated hyaluronan-binding protein (prepared from bovine nasal cartilage aggrecan) were purchased from Seikagaku Corporation (Tokyo, Japan). We used a complete mini protease inhibitor cocktail tablet from Roche Diagnostics $\mathrm{GmbH}$ (Mannheim, Germany).

\section{Experimental animals}

Eight-week-old C57 BL/6 male mice were purchased from Japan
SLC, Inc. (Hamamatsu, Japan) and used for the experiments according to the guidelines of the experimental animal ethics committee of Aichi Medical University (Japan) and Zeria Pharmaceutical Co., Ltd (Japan).

\section{Generation of intradermal injection-induced tissue injury and macroscopic evaluation}

After anesthetizing the mice via intraperitoneal administration of $50 \mu \mathrm{g} / \mathrm{g}$ of pentobarbital sodium (Nembutal; Dainippon Sumitomo Pharma, Tokyo, Japan), the middles of the backs of the animals were shaved to remove the hair (one site on each mouse) and $10 \mu \mathrm{l}$ each of $70 \%(\mathrm{v} / \mathrm{v}) \mathrm{E}, 70 \% \mathrm{E}$ containing $0.1 \%$ dexamethasone (E/Dex), or saline $(\mathrm{Sa})$ were intradermally injected into the shaved sites. The mice were then euthanized with diethyl ether at $5 \mathrm{~h}$ and $1,3,5,7$, and $14 \mathrm{~d}$ after injection. A photograph of each injection site was taken at a fixed magnification, and the area clearly affected by the injection was then measured using Image J Software (National Institutes of Health) ( $\mathrm{n}=7$ for $5 \mathrm{~h}, 1,3$ and $5 \mathrm{~d} ; \mathrm{n}=3$ for 7 and $14 \mathrm{~d}$ ).

\section{Histological analysis}

A. Preparation and staining of histological specimens: At each of the designated times, the portions of skin containing the injection sites were isolated. The tissues were fixed in $10 \%$ formalin at $4^{\circ} \mathrm{C}$ overnight and then embedded in paraffin by using a routine method. The tissues in paraffin were sectioned at a thickness of $4 \mu \mathrm{m}$ and submitted for hematoxylin and eosin (HE) staining and immunostaining as follows: After the samples were deparaffinized and rehydrated, conventional methods were used for HE staining. For immunostaining, sections were deparaffinized, rehydrated, pre-incubated with $10 \%$ goat serum for $1 \mathrm{~h}$ to block nonspecific binding, and incubated with primary antibodies under the conditions described in Table 1 . After being washed several times with phosphate-buffered saline, the sections were incubated with fluorescent-labeled secondary antibodies.

For versican staining, sections were pre-treated with $20 \mathrm{mU} / \mu \mathrm{l}$ of chondroitinase $\mathrm{ABC}$ at $37^{\circ} \mathrm{C}$ for $30 \mathrm{~min}$ before the blocking process. For hyaluronan (HA) staining, sections were incubated with biotinylated HA-binding protein $(1.25 \mu \mathrm{g} / \mathrm{ml})$, and the bound protein was detected with Alexa Fluor 488-conjugated streptavidin as shown in Table 1.

B. Neutrophil and macrophage counting: Neutrophils and macrophages were immunostained with monoclonal antibodies specific to each cell as described above and positive cells were counted within a specified area $\left(370 \mu \mathrm{m} \times 270 \mu \mathrm{m}, 0.100 \mathrm{~mm}^{2}\right)$ magnified at 40 $x$ in which the highest number of positively stained cells was observed, i.e., at the infiltrated region. The data were mean values of the results obtained from 7 mice for each animal group.

\begin{tabular}{|l|l|l|l|}
\hline Antibody & Host & $\begin{array}{l}\text { Dilu- } \\
\text { tion }\end{array}$ & Reaction conditions \\
\hline First & Rat & $1: 50$ & $4^{\circ} \mathrm{C}$, overnight \\
\hline $\begin{array}{l}\text { Biotinylated anti-mouse Ly-6G Neutrophil } \\
\text { marker monoclonal }\end{array}$ & Rat & $1: 50$ & $4^{\circ} \mathrm{C}$, overnight \\
\hline Anti-mouse F4/80 monoclonal & Rabbit & $1: 1000$ & $4^{\circ} \mathrm{C}$, overnight \\
\hline $\begin{array}{l}\text { Anti-mouse versican (GAG beta domain) } \\
\text { polyclonal }\end{array}$ & & & \\
\hline Second & Goat & $1: 2000$ & $\mathrm{RT}, 1 \mathrm{~h}$ \\
\hline \begin{tabular}{l} 
Alexa Fluor 488-conjugated streptavidin \\
\hline DyLight 546-conjugated anti-rat IgG
\end{tabular} & Goat & $1: 5000$ & $\mathrm{RT}, 1 \mathrm{~h}$ \\
\hline $\begin{array}{l}\text { Alexa Fluor 546-conjugated anti-rabbit } \\
\text { IgG }\end{array}$ & Goat & $1: 2000$ & $\mathrm{RT}, 1 \mathrm{~h}$ \\
\hline
\end{tabular}

RT: Room Temperature

Table 1: Antibodies for immunohistochemistry. 
Citation: Kimura M, Sugaya N, Kimata K, Kawachi M, Sawada M, et al. (2012) Effects of Dexamethasone on Tissue Injury and Reconstruction in Ethanol/Steroid Injection Therapy for Allergic Rhinitis. J Aller Ther S5:005. doi:10.4172/2155-6121.S5-005

Page 3 of 9

\begin{tabular}{|c|c|c|}
\hline Target gene & Forward primer & Reverse primer \\
\hline Cxcl1 & $\begin{array}{l}\text { 5'-GCTTGAAGGTGTTGCCCT- } \\
\text { CAG-3' }\end{array}$ & $\begin{array}{l}\text { 5'-AAGCCTCGCGAC- } \\
\text { CATTCTTG-3' }\end{array}$ \\
\hline $\mathrm{CxCl} / 2$ & $\begin{array}{l}\text { 5'-GCGCTGTCAATGCCT- } \\
\text { GAAGA-3' }\end{array}$ & $\begin{array}{l}\text { 5'-TTTGACCGCCCTTGAGA- } \\
\text { GTG-3' }\end{array}$ \\
\hline$I I-1 b$ & $\begin{array}{l}\text { 5'-TCCAGGATGAGGACAT- } \\
\text { GAGCAC-3' }\end{array}$ & $\begin{array}{l}\text { 5'-GAACGTCACACACCAG- } \\
\text { CAGGTTA-3' }\end{array}$ \\
\hline II-6 & $\begin{array}{l}\text { 5'-CCACTTCACAAGTCGGAG- } \\
\text { GCTTA-3' }\end{array}$ & $\begin{array}{l}\text { 5'-GCAAGTGCATCATCGTT- } \\
\text { GTTCATAC-3' }\end{array}$ \\
\hline Spp1 (Opn) & $\begin{array}{l}\text { 5'-TACGACCATGAGATTG- } \\
\text { GCAGTGA-3' }\end{array}$ & $\begin{array}{l}\text { 5'-TATAGGATCTGGGTGCAG- } \\
\text { GCTGTAA-3' }\end{array}$ \\
\hline Has1 & $\begin{array}{l}\text { 5'-TGTGTGTCCTGCATCAGTG- } \\
\text { GTC-3' }\end{array}$ & $\begin{array}{l}\text { 5'-TGGTTGTACCAGGCCTC- } \\
\text { CAAG-3' }\end{array}$ \\
\hline Has2 & $\begin{array}{l}\text { 5'AGTCATGTACA- } \\
\text { CAGCCTTCAGAGCA-3' }\end{array}$ & $\begin{array}{l}\text { 5'-GGCAGGGTCAAGCATAG- } \\
\text { TATCTGAG-3' }\end{array}$ \\
\hline Has3 & $\begin{array}{l}\text { 5'-CATTGAGATGCTTC- } \\
\text { GAGTCTTGGA-3' }\end{array}$ & $\begin{array}{l}\text { 5'-TACATTGCACACAGC- } \\
\text { CAAAGTAGGA-3' }\end{array}$ \\
\hline Vcan & $\begin{array}{l}\text { 5'-ATGGGATTGAAGACACT- } \\
\text { CAGGACAC-3' }\end{array}$ & $\begin{array}{l}\text { 5'-TGAGCAGCG- } \\
\text { GCAAAGTTCAG-3' }\end{array}$ \\
\hline Gapdh & $\begin{array}{l}\text { 5'-TGTGTCCGTCGTGGATCT- } \\
\text { GA-3' }\end{array}$ & $\begin{array}{l}\text { 5'-TTGCTGTTGAAGTCGCAG- } \\
\text { GAG-3' }\end{array}$ \\
\hline
\end{tabular}

Has: Hyaluronan synthase; II: Interleukin; Gapdh: Glyceraldehyde 3-phosphate Dehydrogenase; Opn: Osteopontin; Vcan: Versican

Table 2: Primer sequences for real-time reverse transcriptase polymerase chain reaction.

\section{Extraction of total RNA and quantitative reverse transcriptase polymerase chain reaction analysis}

Skin tissue samples containing the injection sites were collected with an 8 -mm diameter biopsy punch at several time points $(2,3,5$, 24, and $72 \mathrm{~h}$ after injection). The total RNA was extracted from each tissue sample by using TRIzol reagent and purified with a PureLink RNA purification kit according to the manufacturer's instructions (Invitrogen, Carlsbad, CA, USA). A reverse transcription reaction was performed using a high-capacity complementary DNA reverse transcription kit (Applied Biosystems, Foster City, CA, USA) and $2 \mu \mathrm{g}$ of total RNA as a template according to the manufacturer's instructions. The expression levels of Cxcl1/keratinocyte chemokine (KC), $\mathrm{Cxcl} 2 /$ macrophage inflammatory protein-2 (MIP-2), interleukin (IL)- $1 \beta$, IL-6, osteopontin (OPN), HA synthase (HAS)-1, HAS-2, and HAS-3, versican (Vcan), and glyceraldehyde 3-phosphate dehydrogenase (GAPDH) were analyzed with real-time reverse transcriptase polymerase chain reaction (RT-PCR) by using an ABI prism 7700 Sequence Detector (Applied Biosystems). Each oligo (dT) primer is described in Table 2. SYBR Premix DimerEraser (TaKaRa Bio Inc., Kyoto, Japan) was used for amplification and real-time detection of transcript abundance.

\section{Enzyme-linked immunosorbent assay}

The collected skin tissue samples were homogenized in phosphatebuffered saline (PBS) buffer containing a Complete Mini Protease Inhibitor Cocktail (Roche Diagnostics $\mathrm{GmbH}$ ). The homogenates were centrifuged, and the supernatants were subjected to analysis. Cytokines and chemokines in the tissue homogenates were measured using a DuoSet Enzyme-Linked Immunosorbent Assay (ELISA) developmental system kit (R\&D Systems, Minneapolis, MN, USA).

\section{Statistical analysis}

All the data are given as mean values and standard deviation (means $\pm \mathrm{SD}$ ). Differences between E-injection groups and E/Dex-injection groups were examined using the Student's $t$-test. $P$ values $<0.05$ were considered statistically significant.

\section{Results}

\section{Establishment of an in vivo ethanol tissue-damage model by using mouse skin}

We first studied macroscopic level and histological changes after intradermal injection of $70 \% \mathrm{E}, \mathrm{E} / \mathrm{Dex}$, or Sa to determine whether mouse skin could be used as an intramucosal injection model for the nasal mucosa, which is the intended target of the drug, as described previously [2]. Although vesicular swelling appeared at all the sites immediately after intradermal injection, it abated on day 2. From day 1 onward, the Sa-injected sites showed no significant difference from the sites that were not injected. Conversely, the E- and E/Dex-injected sites changed color and shape. On day 1 , the injection site was white; but on day 3 , it became reddish, and the surrounding area began to bulge; scabs then appeared. From day 7 onward, the scabs began to

A
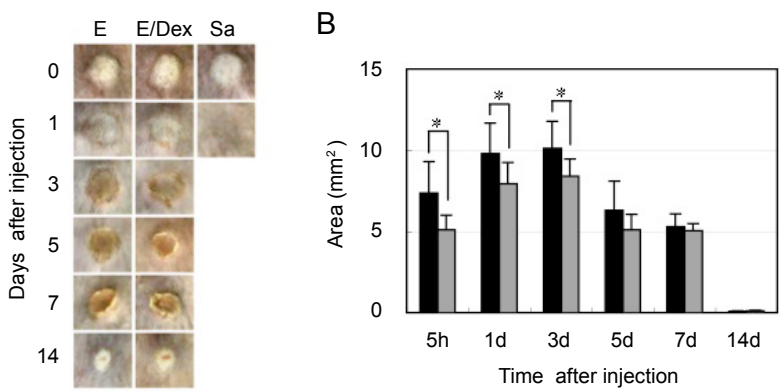

C

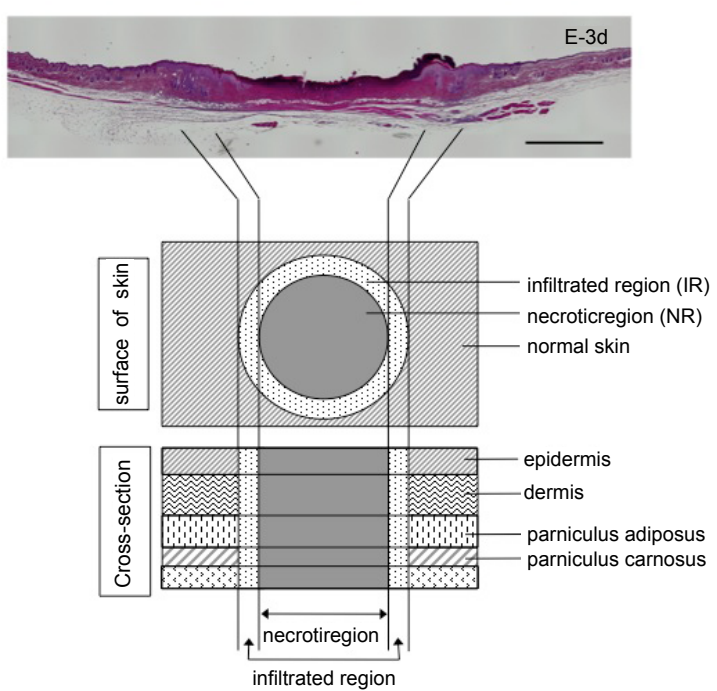

Figure 1: Histopathology of dorsal skin sites injected with $70 \%$ ethanol or $70 \%$ ethanol $/ 0.1 \%$ dexamethasone.

(A) Macroscopic changes in tissue sites generated by the injection of $70 \%$ ethanol $(E)$ and $70 \%$ ethanol/ $0.1 \%$ dexamethasone (E/Dex) were observed at various time points. The injection of saline ( $\mathrm{Sa}$ ) gave temporary vesicular swelling, but such swelling disappeared within $5 \llbracket$ h, and on day 1 the Sa-injected sites showed no significant difference from the sites that were not injected. $(B)$ The injured area of E- and E/Dex-injected sites (filled and open bars, respectively) at each time point were analyzed using Image $\mathrm{J}$ software. The data represent means \pm standard deviation (SD; $n=7$ for $5 \mathrm{~h}$, and 1,3 , and $5 \mathrm{~d} ; \mathrm{n}=3$ for 7 and $14 \mathrm{~d}$ ). No data was obtained for the Sa-injected site, since the injured area was hardly recognized even at $5 \mathrm{~h}$. $(C)$ The dorsal skin sections were prepared at each time point after injection and stained with hematoxylin and eosin (HE), and Schematic diagram represents the injured areas after injection of $E$ or $E / S$. Bars: $1 \mathrm{~mm}$. ${ }^{*} P<0.05$. 
Citation: Kimura M, Sugaya N, Kimata K, Kawachi M, Sawada M, et al. (2012) Effects of Dexamethasone on Tissue Injury and Reconstruction in Ethanol/Steroid Injection Therapy for Allergic Rhinitis. J Aller Ther S5:005. doi:10.4172/2155-6121.S5-005

Page 4 of 9

shrink. On day 14 , only small reddish areas with whitened peripheries remained at both E- and E/Dex-injected sites, indicating that they had largely recovered (Figure 1A). These changes were photographed for quantitative comparisons. The sizes of the injection sites increased up to day 3 and then decreased. The areas of the E/Dex-injected sites were statistically smaller than those of the E-injected sites; however, from day 5 onward, no statistically significant differences between the E/ Dex- and E-injected sites were observed (Figure 1B).

Histological observations of the injection sites were made (Figure 2). No change was observed in Sa-injected sites (Figure 2K). In both the Eand E/Dex-injected groups, the epidermal cells had almost disappeared in the central regions of the injection sites $5 \mathrm{~h}$ after injection, indicating that the tissue in these areas degenerated immediately after the injection (Figure 1C, Figures 2A, and 2B). We tentatively designated these regions as the necrotic regions. Moreover, we observed slight hyperplasia of the epidermis in the peripheral regions of the injection sites, slight hyperplasia of the epidermis was observed on day 1 , and numerous infiltrative cells, many of which were polymorphonuclear neutrophil leukocytes, appeared from the panniculus adiposus to the deep dermal regions (Figures $2 \mathrm{~A}$ to $2 \mathrm{D}$ ). We tentatively named these regions as the infiltrative regions (Figure 1C). The cell number of those infiltrative cells was smaller in E/Dex-injected groups compared to that in E-injected groups (Figures 2C and 2D). Production of collagen fibers had already occurred in these peripheral regions, and this was prominent in the $\mathrm{E} /$ Dex-injection sites (see densely stained areas in Figures 2A and 2B). On day 3 , the epidermis of the infiltration region showed proliferation and thickening, and the epidermis appeared to spread towards the central regions of the injection site (Figures $2 \mathrm{E}$ and $2 \mathrm{~F}$ ). On day 5 , signs of active regeneration of muscle fibers were observed in the panniculus carnosus immediately underneath infiltrative cell aggregates (Figures $2 \mathrm{G}$ and $2 \mathrm{H}$ ). No significant differences in these changes were observed between the E- and E/Dex-injected tissue groups up to day 5 after injection. These results closely resemble histological changes reported for intramucosal injections in guinea pig oral mucosa, which has tissue properties similar to those of human inferior turbinate mucosa $[2,3]$. Consequently, this injection model by using mouse skin is an acceptable substitute.

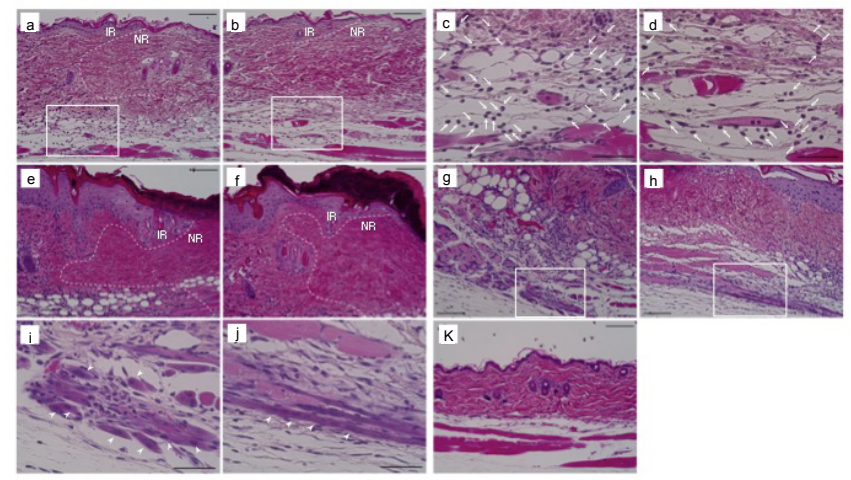

Figure 2: Hematoxylin and eosin staining of border areas of infiltrated and necrotic regions.

Dorsal skin sections, prepared on days $1(A, B, C, D), 3(E, F)$, and $5(G, H, I, J, K)$ after injection of $E(A, C, E, G, I)$, E/Dex $(B . D, F, H, J)$, and $S a(K)$, were stained with $\mathrm{HE}$. Border areas between infiltrated regions (IRs; left side of lines) and necrotic regions (NRs; right side of lines) are indicated by dashed lines. Boxed areas of $A$ and $B$ are enlarged in $C$ and $D$. Boxed areas of $G$ and $H$ are enlarged in $I$ and $J$. Arrows show polymorphonuclear leukocytes. Arrowheads show regeneration regions of muscle fiber. Bars: $A, B, E, F, G, H$ and $\mathrm{K}, 100 \mu \mathrm{m} ; C, D . I$ and $\mathrm{J}, 50 \mu \mathrm{m}$.

\section{Effects of dexamethasone on neutrophil and macrophage recruitment to infiltrated regions}

Both neutrophils and macrophages are known to be recruited to sites of tissue damage and influence various aspects of inflammation and tissue repair [8]. We therefore examined the number and distribution of neutrophils and macrophages in infiltrated regions by performing immunostaining with antibodies specific to each cell type. We also assessed the effects of Dex on the recruitment of inflammatory cells. The positive cells within a single field of view $\left(0.100 \mathrm{~mm}^{2}\right)$ were counted (Figure 3). The number of neutrophils peaked on day 1 and then decreased from day 3 onward; however, the number of neutrophils in the E/Dex-injected group was significantly reduced compared to that in the E-injected group at all measured times $(P<0.01-0.005$; (Figure 3B). Conversely, the number of macrophages increased in a time-dependent manner in both the E/Dex- and the E-injected groups, but from day 1 to day 5 , a higher number was observed in the E/Dex-injected group with statistical significance by day $3(P<0.01)$ but no statistical significance on day 5 (Figure $3 \mathrm{C}$ ). Considering all of these results, we believe that Dex may suppress the initial inflammatory response-pnamely, the recruitment of inflammatory cells during recovery from the tissue lesion caused by E injection.

Effects of dexamethasone on the expressions of chemokine and cytokine induced by intradermal ethanol or ethanol/ dexamethasone injection

Dex has been shown to regulate the activities of KC (CXCL1)

$$
\text { A }
$$

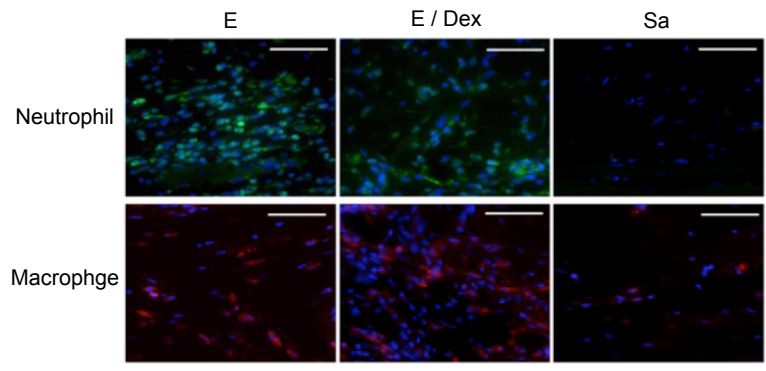

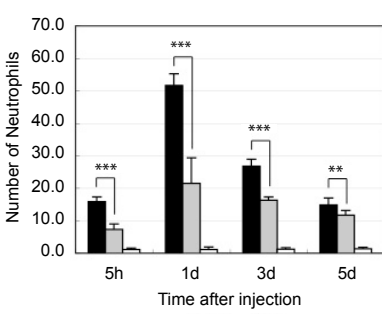

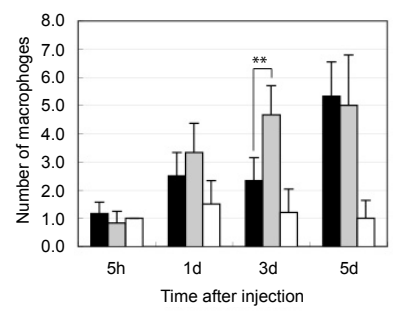

Figure 3: Infiltration of neutrophils and macrophages

Sections of injected skin tissue sites were prepared at the time points indicated and stained with anti-Ly-6G (green; for neutrophils) and anti-F4/80 (red; for macrophages) antibodies. Typical staining patterns for neutrophils and macrophages on day 1 and on day 5 , respectively, were shown $(A)$. 4',6-Diamidino-2-phenylindole (DAPI; blue) was used for counterstaining. The number of neutrophils $(B)$ and macrophages $(C)$ at infiltrated regions were quantified by counting the positive cells within an area $\left(0.100 \mathrm{~mm}^{2}\right)$ magnified at 40x in E (filled bar), E/Dex (gray bar), or Sa (open bar) injection sites. The values are mean \pm SD $(n=7)$. Bars: $50 \mu \mathrm{m} .{ }^{*} P<0.05 ;{ }^{* \star} P<0.005$; ${ }^{* * *} P<0.001$ 
and MIP-2 (CXCL2), which are members of the CXC chemokine family and potent neutrophil chemotactic factors (chemoattractants) $[11,12]$. In addition, IL-1 $\beta$, IL-6, and OPN are thoroughly studied proinflammatory cytokines that stimulate neutrophil and macrophage infiltration [13,14]. Therefore, we examined changes in messenger RNA (mRNA) levels and the gene products of these factors in skin tissues injected with $\mathrm{E}$ and $\mathrm{E} / \mathrm{Dex}$ and evaluated the effects of the addition of Dex on the tissues (Figures 4 and 5).

KC and IL-6 expression was elevated shortly after E and E/Dex injections (Figures $4 \mathrm{~A}$ and $4 \mathrm{D}$ ). The levels of expression reached a peak 3-5 $\mathrm{h}$ after the injection for $\mathrm{KC}$, and less than $2 \mathrm{~h}$ after the injection for IL-6, with levels dropping for both thereinafter. Notably, the expression level of KC in E/Dex-injected samples was lower than that in E-injected samples, and the expression level of IL-6 in E/Dex-injected samples was significantly lower than that in E-injected samples. Consistent with these changes, the amount of $\mathrm{KC}$ protein tended to decrease in E/Dexinjected samples, but in E-injected samples, its levels $24 \mathrm{~h}$ after injection were the same as those $3 \mathrm{~h}$ after injection (Figures $4 \mathrm{~A}$ and $5 \mathrm{~A}$ ). The amount of IL- 6 protein changed over time in a manner similar to that of mRNA, with greater reduction observed in E/Dex-injected samples than in E-injected samples. In particular, the level observed in E/Dexinjected samples dropped to approximately $44 \%$ of that observed in E-injected samples $3 \mathrm{~h}$ after injection (Figures $4 \mathrm{D}$ and 5D).

Expression levels of MIP-2, IL-1 $\beta$, and OPN increased in a timedependent manner after injection with similar tendencies in E- and E/Dex-injected samples, and the expression levels of MIP-2 and OPN were relatively higher than those of the other chemokines and
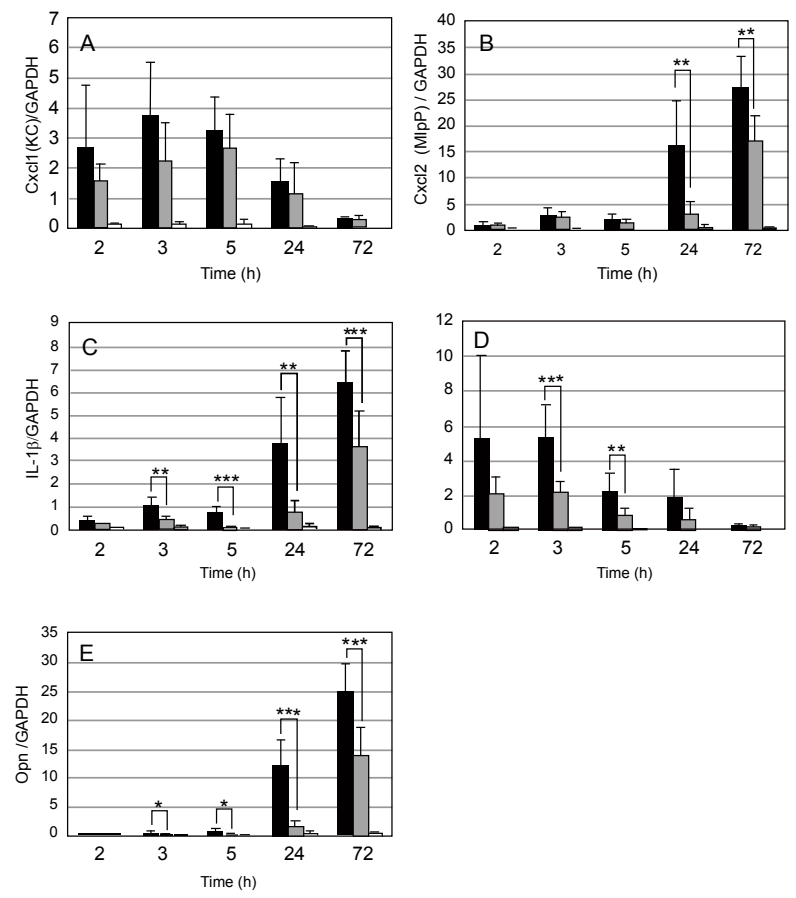

Figure 4: Relative expression levels of messenger RNAs of inflammatory cytokines and chemokines after injection of E, E/Dex, or Sa

Skin tissue samples were collected at different time points indicated after $\mathrm{E}$ (filled bar), E/Dex (gray bar), or Sa (open bar) injection. Relative expression levels of messenger RNA (mRNA) of Cxc/1/KC (A), Cxc/2/Mip-2 (B), II-1 b (C), II-6 (D), and Opn $(E)$ were analyzed as described in Materials and Methods. The values are mean $\pm S D(n=6)$. ${ }^{*} P<0.05 ;{ }^{* *} P<0.01$ ${ }^{* * *} \mathrm{P}<0.005$.
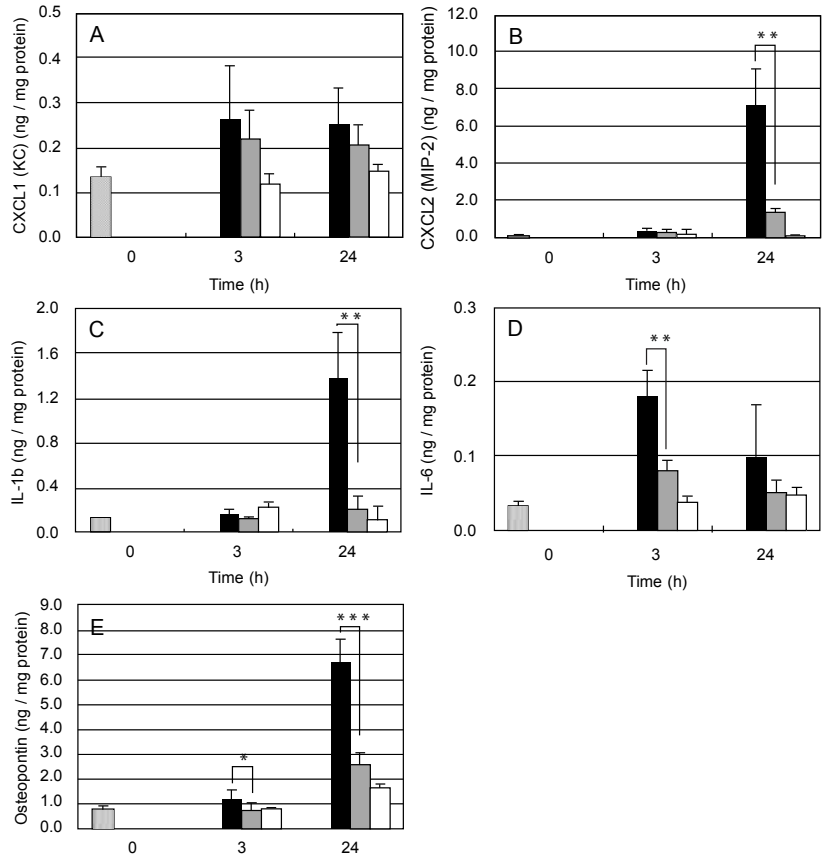

Figure 5: Production of inflammatory cytokines and chemokines in skin tissues after injection of E, E/Dex, or Sa

Skin tissue samples were harvested $3 \mathrm{~h}$ and $24 \mathrm{~h}$ after injection of $\mathrm{E}$ (filled bar), E/Dex (gray bar), or Sa (open bar). The tissues were homogenized, and protein levels of $\mathrm{KC}(A), \mathrm{MIP}-2(B), \mathrm{IL}-1 \beta(C)$, IL-6 $(D)$, and OPN $(E)$ were determined by enzyme-linked immunosorbent assay. The values are mean $\pm \mathrm{SD}$ of the results obtained from 6 mice. ${ }^{*}, P<0.05 ;{ }^{* *}, P<0.005 ;{ }^{* * \star}, P<$ 0.001 .

cytokines. Interestingly, these expression levels increased slightly within a few hours after injection and rapidly and markedly after 24 h. It should be noted again that at this time, mRNA levels in E/Dexinjected samples were considerably lower than those in E-injected samples (Figures 4B, 4C, and 4E). In addition, significantly lower IL$1 \beta$ and OPN levels were observed in E/Dex-injected samples than in E-injected samples within the short period of 3-5 h after injection (Figures $4 \mathrm{C}$ and $4 \mathrm{E}$ ). The amounts of MIP-2, IL-1 $\beta$, and OPN protein, consistent with changes of their mRNA levels, dramatically increased at $24 \mathrm{~h}$ in E-injected samples, whereas they were strongly suppressed in E/Dex-injected samples, decreasing to 19,15 , and $38 \%$ of the results observed in E-injected samples, respectively (Figures 5B, 5C, and 5E). In Sa-injected samples, the mRNA and protein levels of these factor molecules showed no significant changes at any of the time periods examined (Figures 4 and 5).

\section{Extracellular matrix changes induced by intradermal ethanol/ dexamethasone injection and effects of dexamethasone}

Extracellular matrices (ECMs) containing $\mathrm{HA}$ and versican have recently attracted attention because of their involvement in the proliferation, adhesion, and migration of cells and the infiltration of leukocytes, especially neutrophils [15-17]. Therefore, we investigated the immunohistochemical distributions of hyaluronan and versican and the effects of E, E/Dex, and Sa injection on the expression levels of HAS- $1,-2$, and -3 and versican.

In E-injected samples, the mRNA expression level of HAS-1 rapidly increased soon after administration (within $2 \mathrm{~h}$ ) then dropped 
Citation: Kimura M, Sugaya N, Kimata K, Kawachi M, Sawada M, et al. (2012) Effects of Dexamethasone on Tissue Injury and Reconstruction in Ethanol/Steroid Injection Therapy for Allergic Rhinitis. J Aller Ther S5:005. doi:10.4172/2155-6121.S5-005

Page 6 of 9

and returned to a level approximately equal to its original level by 24 $\mathrm{h}$ (Figure 6A). Conversely, the level of HAS-2 increased in a timedependent manner and reached its maximum by $72 \mathrm{~h}$ (Figure 6B). The level of HAS-3, unlike those of HAS-1 and HAS-2, peaked $24 \mathrm{~h}$ after administration (Figure 6C). In E/Dex-injected samples, both the mRNA expression levels of HAS-1 and HAS-2 exhibited similar patterns of increase; however, these levels were significantly lower than those observed in E-injected samples at 3 and $5 \mathrm{~h}$ after injection (Figures 6A and 6B). The level of HAS-3 exhibited a somewhat different expression pattern from those of HAS- 1 and HAS-2. It increased timedependently and reached its peak at $72 \mathrm{~h}$; the values were significantly lower than those observed in E-injected samples at $72 \mathrm{~h}$, but rather higher than those in E-injected samples after $72 \mathrm{~h}$ (Figure 6C). In Sainjected samples, the alteration in mRNA levels was negligible.

HA staining showed that HA production in dermal and epidermal cell layers near the infiltrated regions of E-induced injury was remarkably upregulated compared to that in the E/Dex-induced injury group by $24 \mathrm{~h}$, and a higher intensity of staining was observed in the epidermal cell layers (on day 1 for E- and E/Dex-injected tissues in
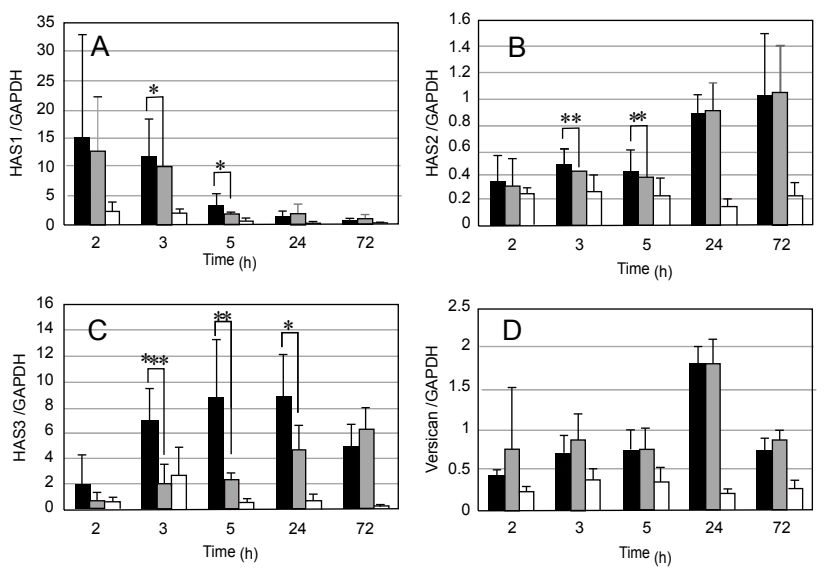

Figure 6: Relative expression levels of hyaluronan synthases and versican mRNA after injection of E, E/Dex, or Sa.

Skin tissue samples were collected at various time points after $\mathrm{E}$ (filled bar), E/Dex (gray bar), or Sa (open bar) injection. Relative expression levels of mRNA of hyaluronan synthase $(H A S)-1(A),-2(B),-3(C)$, and versican (Vcan; $D$ ), were analyzed as described in Materials and Methods. The values are means $\pm \mathrm{SD}(\mathrm{n}=6) .{ }^{*} P<0.05 ;{ }^{* *} P<0.01 ;{ }^{* \star *} P<0.005$
$E$

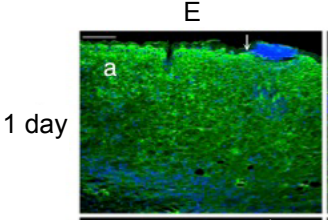

3 day

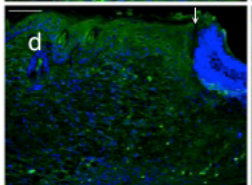

$\mathrm{E} / \mathrm{Dex}$

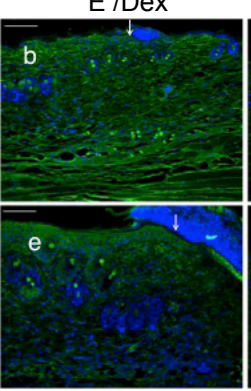

Sa

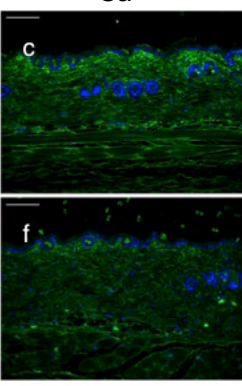

Figure 7: Distribution of hyaluronan after injection of $E, E / S$ of $S a$ Sections of skin tissue sites after injection of $\mathrm{E}(A, D)$, E/Dex $(B, E)$, Sa $(C, F)$ were prepared on days $1(A, B, C)$ and $3(D, E, F)$ and stained using a biotinylated hyaluronic acid-binding protein. DAPI (blue) was used for counterstaining. Borders between infiltrated (left side) and necrotic (right side) regions are indicated by arrows. Bars: $100 \mu \mathrm{m}$.
Figures 7A and 7B). This upregulation disappeared on day 3, however, at which time both E- and E/Dex-injected sites displayed a similar staining intensity (day 3 for E- and E/Dex-injected tissues in Figures $7 \mathrm{D}$ and $7 \mathrm{E})$. In both $\mathrm{E}$ and $\mathrm{E} / \mathrm{Dex}$-injected tissues, distinct staining occurred in the proliferating epidermal cells, whereas in Sa-injected or intact tissues, no significant staining occurred (Figures 7C and 7F).

Although an increasing trend in the mRNA expression level of versican was observed by $24 \mathrm{~h}$ after injection in E- and E/Dex-injected samples, no statistically significant difference was observed between $\mathrm{E}$ and E/Dex -injected samples (Figure 6D). Intense staining of versican in E-injected tissue sites was observed on day 5. In particular, the boundary between the necrotic and the infiltrated regions was distinctly stained (Figure 8). These areas corresponded to the portions of dermis in which skin thickening occurred, enclosing the necrotic regions and, as shown in Figure 2, gross production of collagenous fibers was displayed. No significant difference in the staining patterns between the $\mathrm{E}$ - and the $\mathrm{E} /$ Dex-injected samples was found (data not shown).

\section{Discussion}

In this study, we first attempted to develop a mouse model by using skin as a substitute for nasal mucosa to investigate tissue injury and reconstruction with submucosal E injection therapy. Injection sites on the mouse skin showed somma-like bulging at the periphery, histologically increased proliferation of epidermal cells, and infiltration of neutrophils and macrophages to the regions from the panniculus adiposus to the dermis, which corresponded to the portion from the submucosal layer to the lamina propria in the mucous membrane. Furthermore, the production of fibrous components was observed on day 1 after injection in the dermis near the bulges. Moreover, the inhibitory effects of glucocorticoid on these changes observed in the mouse skin model appeared to be similar to those in a guinea pig mucosa model [3]. Therefore, we believed that this mouse skin model would be useful as a model for studying submucosal ethanol/steroid injection therapy.

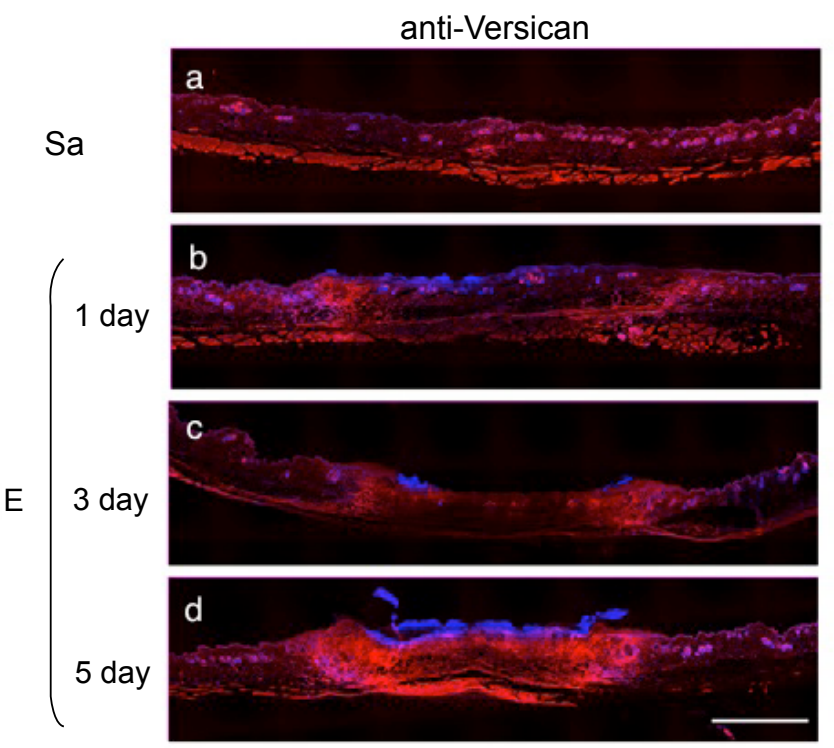

Figure 8: Immunostaining of versican/PG-M

Sections of skin tissue sites after injection of Sa $(A), E(B-D)$, and E/Dex (data not shown) were prepared on days 1,3 , and 5 and stained with anti-versican (GAG-binding beta domain) antibody (red). DAPI (blue) was used for counterstaining. Bars: $1 \mathrm{~mm}$. 
Neutrophils are cells on the front line of defense and immediately respond to inflammatory stimulation such as bacterial infection or tissue damage, and exude and accumulate in damage sites during the early phase of inflammation [5]. In this study, neutrophil infiltration and recruitment to the regions surrounding the injection sites, which we designated the infiltrated region, peaked on the first day after injection, and their levels decreased by approximately $48 \%$ in the presence of $0.1 \%$ Dex compared to those in E-injected groups. Contradictory observations on the effects of glucocorticoid on the chemotaxis of neutrophils have been published, with some claiming that it suppresses chemotaxis $[18,19]$ and others asserting the opposite [20,21]. Caramori and Adcock [22] have explained that the discrepancy is caused by the differences in the detection methods used. In the experiment with $\mathrm{E} /$ Dex injection, $\mathrm{E}$ and Dex were simultaneously injected intradermally into mice, and a distinct reduction in inflammatory cell infiltration into the infiltrated regions was observed, suggesting reduction of chemotaxis. These results and others reporting the suppression of chemotaxis with Dex $[18,19]$ were obtained from in vivo experiments, whereas results reported by Clark et al. [20] and Ackerman et al. [21], which demonstrated no chemotaxis suppression with Dex, were based on in vitro experiments. The variation in results could be caused by differences between in vivo and in vitro experiments. Lomas et al. [18] have shown that smaller amounts of Dex were required to suppress the chemotaxis of neutrophils in in vivo experiments compared to those required in in vitro experiments.

Because neutrophil infiltration responding to inflammatory stimulation is markedly reduced in neutrophil-chemokine receptordeficient mice [23,24], chemokines such as KC and MIP-2 are considered to be involved in the migration of neutrophils. Furthermore, neutrophil activation and migration during inflammation can be suppressed by glucocorticoids $[25,26]$. IL-1 $\beta$ [13] and IL-6 [14], which are pro-inflammatory cytokines, promote neutrophil recruitment into inflammatory sites. In addition, the expression of IL- $1 \beta$ and IL- 6 are both suppressed by glucocorticoids $[27,28]$. OPN is a cytokine with multiple functions. Its expression is promoted in inflammatory sites and it plays an important role in neutrophil infiltration into inflammatory sites [29]. OPN expression can also be suppressed by glucocorticoids [30]. In this study, we found that not only the gene expression of these cytokines and chemokines but also their protein products increased during the early period after intradermal administration of ethanol and, further, were suppressed by the simultaneous administration of Dex (Figures 4,5). Accompanying these changes, inflammatory cell recruitment and accumulation (first the level of neutrophils increased, then macrophages increased) to inflammatory sites were also observed (Figure 3). Considering all of these results, we believe that cytokines and chemokines likely contribute to the increase in the number of these inflammatory cells in infiltrated regions, and that administration of Dex resulted in the marked inhibition we observed. IL-1 $\beta$ is also known to promote migration of macrophages to inflammatory sites [31]. Further, neutrophils have recently been shown to produce MIF, macrophage migration inhibitory factor in the inflammatory sites [32]. Through its induction of the release of CCL2, a potent macrophage chemoattractant from neutrophils, MIF promotes macrophage exudation to the sites [33]. From this knowledge, we can predict that the large number of neutrophils that infiltrate in response to inflammation stimulants promotes further macrophage exudation to inflammatory sites. In this study, however, the number of macrophages detected in the infiltrated regions on days 1 through 3 after administration was higher with the simultaneous injection of Dex and $\mathrm{E}$ than with that of $\mathrm{E}$ alone. In particular, the difference was statistically significant on day
3. Al-Bishri et al. [34] have also reported a similar phenomenon. It is further reported that, in some circumstances, glucocorticoids promote MIF production and, thereby, attenuate anti-inflammatory action of glucocorticoids themselves [35]. Thus, we speculate that from days 1 to 3 of this study, MIF production might have increased temporarily, resulting in the higher macrophage exudation to the infiltrated regions treated with E/Dex than that observed with $\mathrm{E}$ alone.

HA is ubiquitous in the extracellular matrix, and during the migration and infiltration of leukocytes, it regulates cell adhesion and leukocyte activation by interacting with CD44 on cell surfaces $[36,37]$. HAS expression is promoted by IL- $1 \beta$ and other inflammatory cytokines [38,39]. In addition, increases in serum KC and MIP-2 levels have been demonstrated as a result of the intraperitoneal injection of low-molecular-weight fragments of HA [17]. This evidence suggests that $\mathrm{HA}$ is an important molecule in the inflammatory response processes. In this study, we observed an increase in HA and HAS expression during the early period after intradermal $\mathrm{E}$ administration; interestingly, we also observed that these levels markedly decreased with the addition of Dex (Figures 6 and 7). Three isoforms of HAS have been described, and each synthesizes HA with a unique molecular weight [40]. As described above, low-molecular-weight HA can increase the production of cytokines and chemokines [17,41]. Thus, analysis of the molecular weight of HA in our model may be important but remains a subject for future study.

The immunostaining of versican revealed that large amounts accumulated in the boundaries of necrotic and infiltrated regions in both E- and E/Dex-injected groups (Figure 8). Versican is known to be important in basic cell behaviors such as proliferation, adhesion, and migration [15,16,42-44]. Therefore, no significant differences in the accumulation between the E- and E/Dex-injected group suggest the occurrence of active tissue reconstructions in both the inflammatory sites.

Increased production of collagenous fibers, which may be considered a major factor causing tissue bulging, was detected inside of the infiltrated region, especially at sites adjacent to the necrotic region in tissues stained with HE. Histological comparisons of those fibrous molecules showed that those in E/Dex-injected samples increased more than those in the E-injected group. This finding is supported by other evidence that glucocorticoids promote CTGF production and activation [45], and CTGF activates fibroblasts to promote fiber formation [46]. These sites correspond almost exactly to the strongly positive sites for versican staining described above (Figure 8), which sparked our interest in the relationship between glucocorticoids and versican function. Collectively, these findings demonstrate that in mouse skin models, Dex can alleviate E-induced tissue damage via suppression of neutrophil chemotactic chemokine and inflammatory cytokine levels and inhibition of increasing levels of some ECM molecules, which may contribute to inhibition of tissue injury caused by $\mathrm{E}$ administration.

In addition to HA and versican, some adhesion molecules (e.g., integrin, VCAM, ICAM) and heparan sulfate proteoglycans, have recently been reported to play an important role in neutrophil recruitment $[47,48]$. With in vitro experiments by using recombinant human CXCL1, Wang et al. [49] demonstrated that heparan sulfate proteoglycans bind to CXCL1 chemokine and can modulate CXCL1induced downstream signaling and chemotaxis by regulating the binding of CXCL1 to its specific receptor, CXCR2. It has also been reported recently that neutrophil migration induced by MIP-2 decreases in mice with heparanase overexpression [50] and that cytokines such as IL-6 and OPN display heparin-binding activity $[51,52]$. Therefore, 
Citation: Kimura M, Sugaya N, Kimata K, Kawachi M, Sawada M, et al. (2012) Effects of Dexamethasone on Tissue Injury and Reconstruction in Ethanol/Steroid Injection Therapy for Allergic Rhinitis. J Aller Ther S5:005. doi:10.4172/2155-6121.S5-005

detailed analysis of the involvement of these ECM molecules may bring additional findings regarding the effects of glucocorticoids in this therapy. We expect that these findings will, in turn, lead to new methods to inhibit inflammation with substances more effective than glucocorticoids and to the discovery of a novel therapeutic target for inflammation.

In conclusion, we successfully used a mouse skin model to investigate the effectiveness of Dex in submucosal E/steroid injection therapy for allergic rhinitis, a treatment developed by $\mathrm{Wu}$ et al. [4] to address overcome the difficulty in controlling the extent of tissue damage in conventional therapies such as radiofrequency tissue ablation or laser cauterization. Although lesioning of the mucous membrane seems to be important process for this therapy, injection of a mixture of $\mathrm{E}$ and Dex did not result in excessive damage to the skin and significantly decreased expressions of neutrophil chemotactic chemokines and pro-inflammatory cytokines compared with intradermal $\mathrm{E}$ injection alone. The recruitment of inflammatory cells and the expressions of inflammatory extracellular matrix molecules such as HA were also suppressed after injection of the mixture compared to those that developed after treatment with $\mathrm{E}$ alone. The results suggest that the inclusion of a steroid may be the key for the effective application of this new therapy.

\section{Acknowledgments}

We are indebted to Drs. Hiroko Habuchi and Naoko Nagase for providing useful input. This research project was adopted by the Original Seeds Development Business Program of the Japan Science and Technology Agency and was implemented as a joint research project between Aichi Medical University and Zeria Pharmaceutical Co., Ltd. to study the action mechanism of an allergic rhinitis therapeutic (Development Code: Z-207) under development by Zeria Pharmaceutical Co, Ltd. The authors declare no conflict of interest.

\section{References}

1. Wu MD, Taguchi A, Kimura M, Inafuku S (2003) Experimental study of contraction loss effects of mouth mucosa by ethanol injection. 1 KKRQ- IFllQNRND * DNDL. DKR]106: 522-531.

2. Wu MD, Taguchi A, Kimura M, Kuruma T, Inafuku S (2004) Histological study on the effects of the ethanol injection on mouth mucosa contraction loss. $1 \mathrm{KRR}$ - IFllQNRND* DNDL. DIKR]107: 25-32.

3. Taguchi A, Wu MD, Sato H, Nakayama M, Kimura M, et al. (2007) Experimenta study on the effects of steroid on mucosal damage by ethanol injection. J Aichi Med Univ Assoc 35: 87-98.

4. Wu MD, Kimura M, Nakayama M, Inafuku S (2007) A New Treatment Method by Submucosal Ethanol/Steroid (E/S) Injection for Allergic Rhinitis : A Pilo Study. J Aichi Med Univ Assoc 35: 129-146.

5. Nathan C (2006) Neutrophils and immunity: challenges and opportunities. Nat Rev Immunol 6: 173-182.

6. Weiss SJ (1989) Tissue destruction by neutrophils. N Engl J Med 320: 365-376.

7. Dreyer WJ, Michael LH, West MS, Smith CW, Rothlein R, et al. (1991) Neutrophil accumulation in ischemic canine myocardium: insights into time course, distribution, and mechanism of localization during early reperfusion. Circulation 84: 400-411.

8. Chen YX, Sato M, Kawachi K, Abe Y (2006) Neutrophil-mediated liver injury during hepatic ischemia-reperfusion in rats. Hepatobiliary Pancreat Dis Int 5 : 436-442.

9. Rollins BJ (1997) Chemokines. Blood 90: 909-928

10. Gerard C, Rollins BJ (2001) Chemokines and disease. Nat Immunol 2: 108115

11. Luster \$' (1998) Chemokines - Chemotactic cytokines that mediate inflammation. N Engl J Med 338: 436-445.

12. Armstrong DA, Major JA, Chudyk A, Hamilton TA (2004) Neutrophil chemoattractant genes KC and MIP-2 are expressed in different cell populations at sites of surgical injury. J Luekoc Biol 75: 641-648.
13. Lappalainen U, Whitsett JA, Wert SE, Tichelaar JW, Bry K (2005) Interleukin$1 \beta$ causes pulmonary inflammation, emphysema, and airway remodeling in the adult murine lung. Am J Respir Cell Mol Biol 32: 311-318.

14. Keller ET, Wanagat J, Ershler WB (1996) Molecular and cellular biology of interkeukin-6 and its receptor. Front Biosci: d340-357.

15. Zimmermann DR, Dours-Zimmermann MT, Schubert M, Bruckner-Tuderman $L$ (1994) Versican is expressed in the proliferating zone in the epidermis and in association with the elastic network of the dermis. J Cell Biol 124: 817-825.

16. Evanko SP, Angello JC, Wight TN (1999) Formation of hyaluronan- and versican-rich pericellular matrix is required for proliferation and migration of vascular smooth muscle cells. Arterioscler Thromb Vasc Biol 19: 1004-1013.

17. Taylor KR, Trowbridge JM, Rudisill JA, Termeer CC, Simon JC, et al. (2004) Hyaluronan fragments stimulate endothelial recognition of injury through TLR4. J Biol Chem 279: 17079-17084.

18. Lomas DA, Ip M, Chamba A, Stockley RA (1991) The effect of in vitro and in vivo dexamethasone on human neutrophil function. Agents Actions 33: 279

19. Barton AE, Bayley DL, Mikami M, Llewellyn-Jones CG, Stockley RA (2000) Phenotypic changes in neutrophils related to anti-inflammatory therapy. Biochim Biophys Acta 1500: 108-118

20. Clark RA, Gallin JI, Fauci AS (1979) Effects of in vivo prednisone on in vitro eosinophil and neutrophil adherence and chemotaxis. Blood 53: 633-641.

21. Ackerman N, Martinez S, Thieme T, Mirkovich A (1982) Relationship between adherence, chemotaxis and the accumulation of rat polymorphonuclear leukocytes at an inflammatory site. J Pharmacol Exp Ther 221: 701-707.

22. Caramori G, Adcock I (2005) Anti-inflammatory mechanisms of glucocorticoids targeting granulocytes. Curr Drug Targets Inflamm Allergy 4: 455-463.

23. Cacalano G, Lee J, Kikly K, Ryan AM, Pitts-Meek S, et al. (1994) Neutrophi and $B$ cell expansion in mice that lack the murine IL-8 receptor homolog Science 265: 682-684.

24. Milatovic S, Nanney LB, Yu Y, White JR, Richmond A (2003) Impaired healing of nitrogen mustard wounds in CXCR2 null mice. Wound Repair Regen 11 : 213-219.

25. Davenpeck KL, Zagorski J, Schleimer RP, Bochner BS (1998) Lipopolysaccharide-induced leukocyte rolling and adhesion in the rat mesenteric microcirculation: Regulation by glucocorticoids and role of cytokines. J Immunol 161 6861-6870.

26. Schramm R, Schaefer T, Menger MD, Thorlacius H (2002) Acute mast celldependent neutrophil recruitment in the skin is mediated by KC and LFA-1: inhibitory mechanisms of dexamethasone. J Leukoc Biol 72: 1122-1132.

27. Nishida T, Nakai S, Kawakami T, Aihara K, Nishino N, et al. (1989) Dexamethasone regulation of the expression of cytokine mRNAs induced by interleukin-1 in the astrocytoma cell line U373MG. FEBS Lett 243: 25-29.

28. Lee SW, Tsou AP, Chan H, Thomas J, Petrie K, et al. (1988) Glucocorticoids selectively inhibit the transcription of the interleukin $1 \beta$ gene and decrease the stability of interleukin $1 \beta$ mRNA: U-937 promonocytic cell line/posttranscriptional regulation. Proc Natl Acad Sci USA 85: 1204-1208.

29. Koh A, da Silva AP, Bansal AK, Bansal M, Sun C, et al. (2007) Role of osteopontin in neutrophil function. Immunology 122: 466-475

30. Kirton JP, Wilkinson FL, Canfield AE, Alexander MY (2006) Dexamethason downregulates calcification-inhibitor molecules and accelerates osteogenic differentiation of vascular pericytes: Implications for vascular calcification. Circ Res 98: 1264-1272.

31. Pawlinski R, Setkowicz Z, Malodzinska K, Janeczko K (1999) Interleukin-I beta affects the macrophage recruitment and proliferation in the injured brain of 6-day-old rat. Acta Neurobiol Exp 59: 271-278.

32. Daryadel A, Grifone RF, Simon HU, Yousefi S (2006) Apoptotic Neutrophils Release Macrophage Migration Inhibitory Factor upon Stimulation with Tumor Necrosis Factor. J Biol Chem 281: 27653-27661.

33. Gregory JL, Morand EF, McKeown SJ, Ralph JA, Hall P, et al. (2006) Macrophage migration inhibitory factor induces macrophage recruitment via CC chemokine ligand 2. J Immunol 177: 8072-8079.

34. Al-Bishri A, Forsgren S, Al-Thobaiti Y, Sunzel B, Rosenquist J (2008) Effect of betamethasone on the degree of macrophage recruitment and nerve growth 
Citation: Kimura M, Sugaya N, Kimata K, Kawachi M, Sawada M, et al. (2012) Effects of Dexamethasone on Tissue Injury and Reconstruction in Ethanol/Steroid Injection Therapy for Allergic Rhinitis. J Aller Ther S5:005. doi:10.4172/2155-6121.S5-005

factor receptor p75 immunoreaction during recovery of the sciatic nerve after injury: an experimental study in rats. Br J Oral Maxillofac Surg 46: 455-459.

35. Calandra T, Bernhagen J, Metz CN, Spiegel LA, Bacher M, et al. (1995) MIF as a glucocorticoid-induced modulator of cytokine production. Nature 377: 68-71.

36. Khan Al, Kerfoot SM, Heit B, Liu L, Andonegui G, et al. (2004) Role of CD44 and hyaluronan in neutrophil recruitment. J Immunol 173: 7594-7601.

37. Johnson P, Ruffell B (2009) CD44 and its role in inflammation and inflammatory diseases. Inflamm Allergy Drug Targets 8: 208-220.

38. Yamada Y, Itano N, Hata K, Ueda M, Kimata K (2004) Differential regulation by IL-1beta and EGF of expression of three different hyaluronan synthases in oral mucosal epithelial cells and fibroblasts and dermal fibroblasts: quantitative analysis by using real-time RT-PCR. J Invest Dermatol 122: 631-639.

39. Vigetti D, Genasetti A, Karousou E, Viola M, Moretto P, et al. (2010) Proinflammatory cytokines induce hyaluronan synthesis and monocyte adhesion in human endothelial cells through hyaluronan synthase 2 (HAS2) and the nuclear factor-kappaß (NF-kappa $\beta$ ) pathway. J Biol Chem 285: 2463924645

40. Itano N, Kimata K (2002) Mammalian hyaluronan synthases. IUBMB Life 54:195-199

41. Termeer CC, Hennies J, Voith U, Ahrens T, Weiss JM, et al. (2000) Oligosaccharides of hyaluronan are potent activators of dendritic cells. J Immunol 165: 1863-1870.

42. Yamagata M, Saga S, Kato M, Bernfield M, Kimata K (1993) Selective distributions of proteoglycans and their ligands in pericellular matrix of cultured fibroblasts. Implications for their roles in cell-substratum adhesion. J Cell Sci 106: 55-65.
43. Yamagata M, Shinomura T, Kimata K (1993) Tissue variation of two large chondroitin sulfate proteoglycans (PG-M/versican and PG-H/aggrecan) in chick embryos. Anat Embryol (Berl) 187: 433-444

44. Wight TN (2002) Versican: a versatile extracellular matrix proteoglycan in cell biology. Curr Opin Cell Biol 14: 617-623.

45. Dammeier J, Beer HD, Brauchle M, Werner S (1998) Dexamethasone is a novel potent inducer of connective tissue growth factor expression. Implications for glicocorticoid therapy. J Biol Chem 273: 18185-18190.

46. Fraziert K, Williams S, Kothapalli D, Klapper H, Grotendorst GR (1996) Stimulation of fibroblast cell growth, matrix production, and granulation tissue formation by connective tissue growth factor. J Invest Dermatol 107: 404-411.

47. Parish CR (2005) Heparan sulfate and inflammation. Nature Immunol 6: 861 862.

48. Ley K, Laudanna C, Cybulsky MI, Nourshargh S (2007) Getting to the site of inflammation: The leukocyte adhesion cascade updated. Nat Rev Immunol 7: 678-689.

49. Wang D, Sai J, Richmond A (2003) Cell surface heparan sulfate participates in CXCL1-induced signaling. Biochemistry 42: 1071-1077.

50. Massena S, Christoffersson G, Hjertström E, Zcharia E, Vlodavsky I, et al (2010) A chemotactic gradient sequestered on endothelial heparan sulfate induces directional intraluminal crawling of neutrophils. Blood 116: 1924-1931

51. Mummery RS, Rider CC (2000) Characterization of the Heparin-Binding Properties of IL-6. J Immunol 165: 5671-5679.

52. Scatena M, Liaw L, Giachelli CM (2007) Osteopontin: A Multifunctiona Molecule Regulating Chronic Inflammation and Vascular Disease. Arterioscler Thromb Vasc Biol 27: 2302-2309.
This article was originally published in a special issue, Allergic Rhinosinusitis handled by Editor(s). Reginald F. Baugh, University of Toledo, USA. 